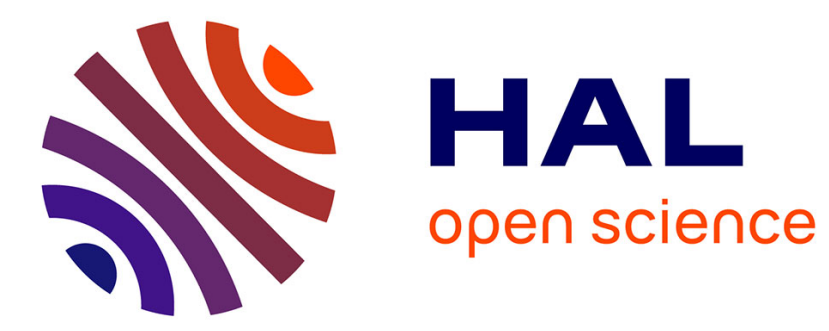

\title{
COMPUTER AIDED TEACHINGS SYSTEMS
}

Jean-Paul Becar, Jean-Charles Canonne, Marika Seppälä, Alain Mayeur

\section{To cite this version:}

Jean-Paul Becar, Jean-Charles Canonne, Marika Seppälä, Alain Mayeur. COMPUTER AIDED TEACHINGS SYSTEMS. EDULEARN 2016, Jul 2016, Palma de Majorca, Spain. hal-02508284

\section{HAL Id: hal-02508284 \\ https://uphf.hal.science/hal-02508284}

Submitted on 14 Mar 2020

HAL is a multi-disciplinary open access archive for the deposit and dissemination of scientific research documents, whether they are published or not. The documents may come from teaching and research institutions in France or abroad, or from public or private research centers.
L'archive ouverte pluridisciplinaire HAL, est destinée au dépôt et à la diffusion de documents scientifiques de niveau recherche, publiés ou non, émanant des établissements d'enseignement et de recherche français ou étrangers, des laboratoires publics ou privés. 


\title{
COMPUTER AIDED TEACHINGS SYSTEMS
}

\author{
Jean-Paul Bécar ${ }^{1}$, Jean-Charles Canonne ${ }^{2}$, Marika Seppälä ${ }^{3}$, Alain Mayeur ${ }^{4}$ \\ ${ }_{1,2,4}$ University of Valenciennes (France) \\ ${ }^{3}$ University of Applied Sciences of Pori (Finland)
}

\begin{abstract}
The main subject of this paper deals with massive online open courses -MOOCs- in short. That is the use of computers to learn and teach. The term computer refers to internet, common and specialized software and mostly new ways to communicate and to have flexible access to any information. The paper is focusing on two main topics. First, three completed experiments of MOOCs in science and in human science have been supervised by the first three authors. Second, the general content and containers of MOOCs are here presented involving the French case on digital university on what the last author is working as an expert.

The two first experiments on MOOCs are based on robotics and computer science. They are concerned with a group of twelve bachelor of technology students in electrical engineering. The MOOCs certificate takes a part of the final assessment. The third MOOC offers lessons on the leadership behaviour. A group of twelve students in bachelor of technology in Environmental Engineering domain have taken part to a leadership and management course. This course included straight at the starts, a participation to a MOOC. In all three presented examples, the teachers were always helping students. Weekly meetings and briefing planned in the agenda make the students more confident to themselves, give the teacher the opportunity to focus on any growing up difficulty and improve students behaviour to share knowledge. The feedback of the use of MOOCs is launching new questions about the impact of learning, teaching and evaluating online.

The MOOCs interest is getting up due to the free, easy and available access to numerous domains covering sciences, philosophy, literature, management. MOOCs could be an answer for the knowledge worldwide sharing. The MOOCs providers are mainly coming from USA, UK, Germany, Spain and France. That implies a large amount of universities worldwide are collaborating with the providers. In France, the digital University platform has been launched at the end of 2013. Courses are available since 2014. They cover domains as Mathematics, Philosophy, History, Public Health. Within two years, one million of attendees took part to these online courses. The last author of this article offers his experience as an expert in digital University. The validation of the online certificate, the development of portfolio are two important subjects that deal with MOOCs.
\end{abstract}

Keywords: Mooc, e-learning, digital university, digital technology, online certificates.

\section{INTRODUCTION}

As the student motivation is vanishing, the teacher's energy should grow in order to keep students on the educational trail. Massive education, running technology, educational tools, easy and quick access to old and recent information on any domain are some of the reasons that motivate conversely the teacher to find new acquiring methods. Online lessons are one of them.

The main subject of this paper deals with three recent completed applications based on massive online open courses -MOOCs- in short. MOOCs are provided by websites. The MOOC's interest is getting up due to the free, easy and available access to numerous domains covering sciences, philosophy, literature, management. MOOCs could be an answer for the knowledge worldwide sharing[1]. In an interview, Bill Gates predicts how on line courses can radically improve education by 2030 (http://www.theverge.com) and recommands to flip the classroom.

The section two deals with the general aspects of MOOCs. About ten thousands students over the world participate to any MOOC. During eight weeks, once a week, at their own rhythm, the attendees watch ten minutes online lessons, answer quizzes and make homework for training, discuss on forum, ask questions to the community and share knowledge. Students also have to reply to official quizzes and to send homework. These official and online assessments required for the certificate validate the 
competences. The MOOCs providers are mainly coming from USA, UK, Germany, Spain and France. That also implies that a large amount of universities worldwide are collaborating with the providers.

The section three is concerned with recent completed examples. The two first take place in a French Institute of Technology and the third one in a Finnish University of Applied Sciences. Both universities have been collaborating over fifteen years. The first online lessons are concerned with the robotics vision subject. A group of ten students in the bachelor of Technology course participate to the sessions. In their syllabus a mentored project has to be completed before the end of semester and the robotics vision domain is one of the subjects proposed. And each week, in addition to their online lessons, a 2 hours meeting is planned in the computer room with one or two teachers if necessary. As results, all students got the certificate.

The second series of MOOCs lectures deal with an initiation to an enhanced programming language. A group of twelve students in the bachelor of Technology course participate to the sessions. With a little help from teachers main students obtain the final certificate.

The third MOOC dealt with the individual leadership behaviour. It concerns a group of twelve students in the bachelor of Energy and Construction. This MOOC is integrated as a part their module "Leadership and project management" and includes a weekly meeting. The objectives are to articulate the student's personal values and leadership analysis. Student has to cultivate supportive relationships with people, and continually experiments with how to get things done, trying to align his actions with these values, to produce positive sustainable change. Most of students obtain the certificate.

The three examples confirmed that the physical presence of the teacher was essential. Nevertheless, the teachers and the teachings methods should take account of the most recent technology based on computer communications and software. The development of MOOCs platforms is growing in that sense. The MOOCs interest is getting up due to the free, easy and available access to numerous domains covering sciences, philosophy, literature, management. MOOCs could be an answer for the knowledge worldwide sharing.

In France, a digital University platform has been launched at the end of 2013. Courses are available since 2014. They cover domains as Computer science, Philosophy, History, Public Health. Within two years, one million of attendees took part to the online courses. The last author of this article offers his experience as an expert in digital University.

The last section draws some conclusion. The authors discuss on the feedback in the use on MOOCs inside classroom from the point of view of students as from the point of view of the teachers. In particular, important questions as prevent from online cheating then ideas for assessments are examined.

\section{GENERAL ORGANISATION OF MOOCS}

\subsection{Development of on line courses for mass education.}

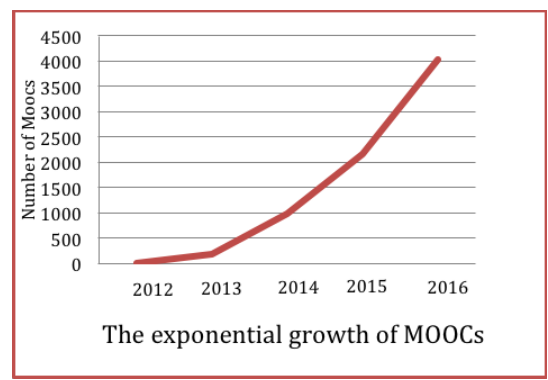

Figure 1 : The rise of MOOCs

The acronym MOOC stands for Massive Open Online Courses. It means that lessons not lectures, are given to anyone on the internet for free except the connection to the world wide web and a computer with useful software. That is making the golden era of learning said Bill Gates. The figure 1 shows the exponential growth of MOOCs delivered by the websites.

Based on this model, an estimation of two hundred thousand MOOCs could happen in 2020. 
The rise of MOOCs requires new providers. The big three, Coursera, edX and Canvas in USA are followed by others shown in table 1. With Universities as partners, the providers deliver their online courses in numerous domains. They cover fields as computer science, cryptography, robotics, management, financial markets, digital marketing, literacy, big data, quantum mechanics, signal processing, foreign languages, sustainable development and music. For any course, over ten thousands worlwide attendees participate to the lessons. The structure of a MOOC is rather the same whatever the domain. It is described as follows.

\begin{tabular}{|l|l|l|}
\hline \multicolumn{1}{|c|}{ MOOCs providers(country) } & \multicolumn{1}{|c|}{ website } & type \\
\hline Coursera (USA) & $\underline{\text { https://www.coursera.org/ }}$ & Commercial \\
\hline edX (USA) & $\underline{\text { http:///edx.org/ }}$ & Non-profit \\
\hline canvas.net (USA) & $\underline{\text { https://www.canvas.net }}$ & commercial \\
\hline FutureLearn (UK) & $\underline{\text { http://futurelearn.com/ }}$ & Non-profit \\
\hline Iversity (Germany) & $\underline{\text { http://www.iversity.org/ }}$ & commercial \\
\hline FUN (France) & $\underline{\text { https://www.fun-mooc.fr }}$ & Non-profit \\
\hline Miriada x (Spain) & $\underline{\text { https://miriadax.net/ }}$ & commercial \\
\hline Udacity (US) & $\underline{\text { https://www.udacity.com/ }}$ & commercial \\
\hline Khan-Academy(US) & $\underline{\text { https://www.khan-academy.fr/ }}$ & Non-profit \\
\hline
\end{tabular}

Table 1 : Main MOOCs providers

\subsection{The schedule of any MOOC.}

During 8 weeks, each week the attendee watches video lessons at his own rythm. The lesson ends on Sunday evening and a new one is starting on Monday. During the week, for practice the learner does homeworks, answers to quizzes, shares knowledge with others, asks questions to authors. At the end of the week, an official quizz is proposed. The results will be counted for the final certificate.

The evaluation ends the teaching process. It must guarantee the quality of the titles given to the students. For any MOOC, a final examination then a certificate validate the skills. Altough the certificate confirms the success of the assessment, the identity behind the computer is not certified. Internet eases cheating. Some providers are trying to fix the problem. The big 3 providers propose since a couple of years their own credentials : nanodegrees, Specialisations, Xseries for Udacity, Coursera, edX respectively. The credentials have become a new source of revenue. The background requires an additional organisation in order to settle and authentify the examination.

Not to be overtaken by the technology and its applications in learning process, to make their department attractive and modern regarding the teaching methods in use, to discuss and share on actual experiences are the main motivation of the authors. The next section deals with applications of MOOCs.

\section{ARE YOU EXPERIENCED WITH MOOCS}

This section deals with 3 completed MOOCs two in France about science and the third one in Finland about human behavior. The reader can find more details on the two first in [2],[3]. 


\subsection{MOOCs in robotics and vision}

Professor Peter Corke and the Queensland University of Technology have organized a MOOC called An introduction to Robotics (http://petercorke.com/). This MOOC was based on a part of the book written on this subject by Peter Corke[4]. An electronic version of this part of the book was provided if you enrolled the MOOC. A free access to Matlab@ was also provided for the duration of the MOOC. In addition to the MOOC, a non compulsory robotic challenge based on Lego@ Mindstorm@ brick was proposed. A group of twelve students and three teachers from our Electrical Enginering department have enrolled the MOOC. Before the beginning of the MOOC, lectures have been given by the Mathematics teacher about linear algebra and about Matlab@.

During the MOOC, we had each week half a day for teachers supervising: English comprehension with the English teacher, Mathematics explanations with the Mathematics teacher and Matlab@ help with the Control Process teacher. This weekly meeting took place in a friendly room equipped with a coffee machine. Students and teachers looked at the videos together and discussed about them. Quiz and programs had to be done at home, but students were invited to work together, and could ask for questions either by mails to their teachers, either by questions on the forum of the MOOC.

This participation to the MOOC have complied with the objectives of the mentored project as described in our syllabus: that are multidisciplinary activities, practical application of knowledge, project management with deadlines and finally teamwork.

The participation to the MOOC has even surpassed the targets.

First of all, students have improved their English language.

On another point, the relationship between teachers and students, as well students and students has been improved by these eight weeks of common adventure. Teachers have played coaches, and students players.

More than fifty per cent of students obtained their certificate from the University of Queensland. This success is mainly due to the local presence of teachers. This certificate from an Australian University will be important for them when they will search for a placement or for a job.

This experience was so successful that students ask us to participate to the second MOOC organised by Peter Corke on Vision, and that other teachers and students joined us for this second adventure.

The MOOC "Robotic Vision" has also been organized by Professor Peter Corke and the Queensland University of Technology.

Locally, for the second MOOC, four other students and their teacher working on another mentored project joined us. We were also joined by four Finnish students who were on an Erasmus placement for four months in our department. In the same way the first MOOC had been a good opportunity to make teachers and students work together, the second MOOC made French and Finnish students work together. Once again the second experience proved the importance of local teachers to organize the meetings between all the staff.

The success of the MOOC in robotics drives the students and their teachers to launch the participation to another MOOC taught in french language in order to free students from the english language difficulties[2].

\subsection{A programming language}

A group of second grade bachelor students decided to take part to the $\mathrm{C}++$ programming language lessons (https://www.coursera.org/course/initprogcpp) given through a MOOC by the Ecole Polytechnique Fédérale de Lausanne (https://www.epfl.ch/). Locally, two lecturers manage the group of 15 students and participate both to the MOOCs[3,4]. All week long, students do not hesitate to ask technical questions on their current problems.

The Université Polytechnique de Lausanne organizes two MOOCs dealing with the $\mathrm{C}++$ programming language. We are concerned here with the first one, which is an initiation for students to the high level programming language $\mathrm{C}_{++}$. The second $\mathrm{MOOC}$ is an initiation to Oriented Object Programming. The first MOOC lasts eight weeks, requiring over five hours work per week. No previous knowledge is needed. Each week session ends with a quiz, a couple of practical exercises and a homework program to be uploaded within a fixed schedule. A final certificate is given to the students who completed all works in time. 
The figure 4 sums up some of lecturers' tasks done in that background. Some of these tasks are well known[5]. The step 1 is concerned with all MOOC long. It includes the general organization of activities. The step 2 starts when the official is launched on the internet. The step 3 is one of the most important part of the MOOC. At one point students wanted to stop learning lessons due to the difficulty getting harder suddenly. At that time, they asked a technical help from the lecturers. One of them gave them not exactly the solution to homework but a schematic solution using a block representation of algorithm taught at the University. The effect was immediate. All students shared the answer and continued the MOOC lessons. But, the motivation had been restored just a little bit in order to end the MOOC see point 4 in Fig.4. The students motivation can't be measured but estimated. The chosen indicator is given by the number of questions getting up or down during the MOOCs session.

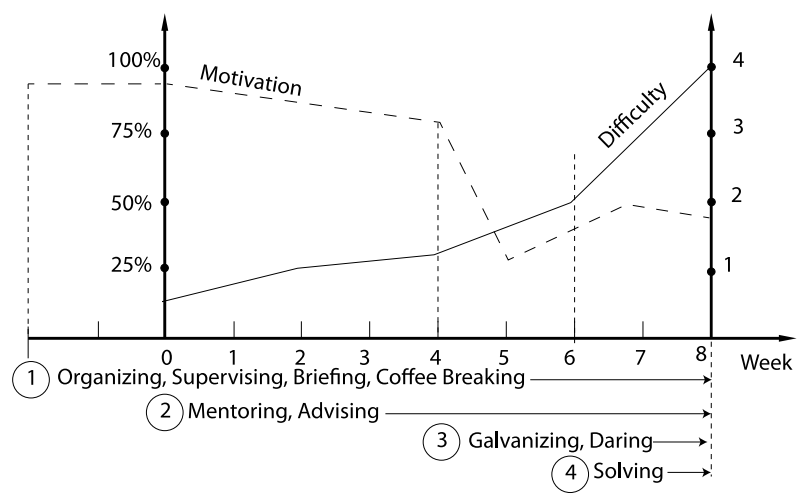

Fig. 4 : Teachers tasks for MOOCs

Even if they are not written in the syllabus, the previous completed MOOCs will provide an added value to the student curriculum.

The last experience details an integration of a MOOC in an academic course. The subject is concerned with the leadership.

\subsection{A leadership and project management course}

In the SAMK in particular and in Finland in general, universities are using the most recent technology applications. In this example, a course in leadership and project management has been proposed to a group of twelve students in Bachelor of Technology in Environmental Engineering. The group includes exchange students. An international MOOC mainly about leadership covers a part of a studies and the final assesment. Additional contact lessons of leadership and project management are organized every week.

Thanks to an expert help, the selected mooc (https://www.coursera.org/course/totalleadership) fulfills some conditions as the quality of the providers and online lessons, the timing of the lessons fitting the local agenda.

The Warton School of the University of Pennsylvania (https://www.wharton.upenn.edu) offers a mooc titled Better Leader, Richer Life where a Total Leadership approach is given. It covers the learning of how to articulate its own values and personal leadership vision, how to cultivate supportive relationships with people([6],[7])

This step-by-step method for pursuing what professor Stewart Friedman calls "four-way wins" has enabled people all over the world to become more successful and satisfied leaders in all parts of life: work, school, home, community, and the private self.

This practical course has been taught to thousands of students at Wharton and elsewhere by Friedman since 2001. Over 94,000 enrolled in our first two sessions of this course in 2014, and the instructor rating for it was second-highest of all University of Pennsylvania courses on Coursera.

In practice the course is planned for ten weeks with a weekly deadline for assesments. Locally, one day of the course lectures and video tutorials was reserved for MOOC either to work in the class room or at home. Moreover, as the deadline for tasks has been fixed on Sunday, every Monday a briefing 
offers the opportunity to discuss, to add some justifications or explanations linked to the course subjects. The following week is reserved for peer reviews. It means that students must explain and justify their ideas, choices and decisions on three given subjects. Half of them obtained the final certificate. All gave their opinion on that special MOOC during an open discussion meeting. Two are reproduced below for further discussions and improvements.

The first one : "It was not easy for me to arrange dialogues with my stakeholders which was one of the tasks. But at the same time I got the idea that this kind of activity might be really needed somewhere in the future, so after all It does not matter if I could not arrange a proper dialogues during the course, I still learned something."

The second one: "As the course is originated in Pennsylvania where the culture is totally different than in north of Europe, it was not easy to accept the style of how the course was conducted. To complete the tasks, sometimes it took much more time than I expected. But also there were many things that I liked about this course."

\section{THE FRENCH DIGITAL UNIVERSITY}

For a couple of years, the french educational system has got involved in the digital university (http://www.sup-numerique.gouv.fr). The system is trying to catch up the vanishing horizon of the growing technology. An educational portal is now working since 3 years. It offers new educational approaches using the technology, the computers and the internet(https://www.fun-mooc.fr) The last author of the article is an expert in this domain. His main activities are pointing on digital tools built by the french educational community. It covers the digital university, the learning managements systems for national and international issue and the information management systems.

In order to change the behavior of learners and teachers in higher education system, the teaching and learning approaches will adapt themselves to the new system to make the university more attractive. The innovation will come from stakeholders as well as the organisors meaning that the digital university should propose new courses for emerging jobs. Web designers, profile designer, digital marketing designers, Mooc designers are some examples.

The digital university should offer too a lifelong learning system trying to turn the learner as an actor of his own education. New teaching tools are emerging since a couple of years or months. In digital education, video games, serious games, adaptative learning, reverse learning or flip classroom, collaborative spaces, resource sharing, grading, networking, Small Private Online Courses -SPOC- in short or Corporate Online Open Course -COOC- are changing the galaxy of the educational system.

As the internet and computers ease the access to knowledge wordwide, it has also side effects. Cheating is common. For MOOC, the evaluation must guarantee the quality of the titles given to the students. Recently, FUN MOOC is launching a system to a long distance checking for the learner identity. This is already applied to two MOOCs -from manager to leader- and -contemporary problems in Economics-. The background requires an additional organisation to settle and validate the examination. The attendee will pay sixty euros. Those fees are known as a threshold in online payment.

Regarding the big data provided by the net, some learners are encouraged to siphon websites. They paste the documents straight in their work. From now the document are regarded as their own research. To prevent this type of coarse cheating, our university is using a new tool to check the plagiarism. A software helps to detect plagiarism (https://www.compilatio.net). It has been used at the Institute of Technology since two years mainly for student work in companies and for personal student researches on given and mentored project. The immediate effect was to drop down the ratio of plagiarism and rise up the personal work.

The digital university also offers to learners an information management system (http://www.imsglobal.org). The portfolio of skills is also named cyberportfolio or eportfolio. The eportfolio is a student personal space. It contains the proof of all competences, acquired knowledge from educational systems. It also includes the personal and professional experience. The eportfolio should improve the connection between the universities and companies. It should better track competences and enhance the learning experience. A common idea suggested by authors is what the user is learning while writing his own portfolio. 


\section{CONCLUSION}

The article deals with new learning and teachings approaches. The most recent described and applied has been chosen here. After a short presentation on what is a MOOC and which are the stakeholders and providers, the authors point out three completed MOOCs in robotics, computer science and leadership management. Then the French experience on digital university is discussed.

While the use of computers and the internet is becoming common for many things not only in education, there are some important questions emerging from the recent ways to learn and teach. $A$ list of query follows:

Is it the end of free certificates?

Do employers trust any MOOC certificate rather diploma?

Is the checking of identity of attendees faithfull?

Are we freeing of physical teacher definitively for a same result?

Use MOOC in flip classroom or classical lessons

Must the new teacher generation collaborate within different domains or no?

Are the data in a eportfolio enough protected?

Are the MOOC platforms ready to vanish teachers while giving a global learning environment rather a system of courses delivery?

New trends of MOOCs answer partially to these questions as :

Self paced courses allowing the learner to participate to a planned MOOC, to stop learning and to restart from the last stop even later after the deadline of MOOC giving thus more flexibility (https://www.class-central.com/courses/selfpaced) .

Nanodegrees will be given to those who completed a number of defined MOOCS. The big three recently starts this option.

The computer aided teachings systems are offering a wide range of knowledge for higher education for all age students at any part of the world at any time. We must jump into this educational high speed train rather stay on the platform.

\section{AKNOWLEDGMENTS}

The authors would like to warmly thank the University of Valenciennes and the Institute of Technology and the University of Applied Sciences of Pori for giving the work environment and in particular the availability of the technical staff.

\section{REFERENCES}

[1] Wheeler S., Gerver R., Learning with 'e's: educational theory and practice in the digital age, Crown House Publishing, 2015, ISBN 978-1-84590-939-0

[2] Sams, A., \& Bergmann, J. (2013). Flip Your Students' Learning. Educational Leadership, 70(6), 16-20.

[2] Canonne J.-C., Jean-Paul Bécar J.-P., Fratu A., Fratu M. , A robotics experience with mooc, Iceri 2015 proceedings, pp 6420-6425, 2015,ISBN: 978-84-608-2657-6.

[3] Canonne J.-C., Jean-Paul Bécar J.-P., Fratu A., Fratu M. , Are local teachers required within moocs sessions? INTED2016 Proceedings, pp 3387-3394, 2016, ISBN: 978-84-608-56177 ISSN: $2340-1079$

[4] Corke P.I., "Robotics, Vision \& Control”, Springer 2011, ISBN 978-3-642-20143-1.

[5] Fochtman, M. M. (2006). Managing, supervising, advising, and mentoring: Each requires unique hat for the professional. Campus Activities Programming (38), 7, p47-52 
[6] Friedman S.D., Be a better leader, Have a rich Life, , Harvard Business, 2008.

[7] Leading the life you want: skills for integrating work and life, Harvard Business, 2014 